H Raeisi, N Makoolati. Nursing, Shiraz University of Medical Sciences, Shiraz, Iran

The development of Pediatric Advanced Life Support and Advanced Pediatric Life Support have demonstrated new interest in emergency care of pediatrics and have made it imperative to have data that define the potential risks and preventive strategies. The different Prehospital recording sheets and tapes were reviewed retrospectively over a 12-month duration from March 2011. Patients under 19 years of age were studied in a service area with a population of 670,000 . A total of 1,115 records were analyzed, representing approximately $12 \%$ of all ambulance runs. This is sharply in contrast with the fact that the pediatric age group represents $32 \%$ of the population. Of the cases, $32.7 \%$ were in the trauma category. The largest trauma group was motor vehicle accidents in the adolescent age group. Male patients were dominant in the trauma cases. Medical disorders were the major reason for prehospital care in the very young. The demand for emergency medical services (EMS) occurred mainly during the summer months and on the first week of the year (NOWROOZ) and weekends. More than 62 percent of all EMS pediatric calls happened during the hours of 1:00 pm to 9:00 $\mathrm{pm}$. Resuscitation of 10 cases of pediatric prehospital arrest resulted in no survivors to hospital discharge mostly because of drowning, foreign body obstruction and falling down.

\section{EFFECT OF PARENTS' SHIFT WORK ON STRENGTHS AND BEHAVIORAL PROBLEMS OF THEIR CHILDREN, AGED 7-12 YEARS OLD IN TEHRAN, IRAN}

doi:10.1136/archdischild-2012-302724.1896

'Z Godarzi, ${ }^{2} 0$ Bakhti, ${ }^{3} \mathrm{AR}$ Shamshiri, ${ }^{4} \mathrm{~F}$ Youssefi. ${ }^{1}$ Pediatric \& Neonatal Intensive Care Unit, Faculty of Allied Medical Sciences, Tehran University of Medical Science, ${ }^{2}$ Pediatric Bone Marrow Transplantation; ${ }^{3}$ Epidemiology and Biostatistics School of Public Health, Tehran University of Medical Sciences; ${ }^{4}$ Health Education, Faculty of Allied Medical Sciences, Tehran University of Medical Science, Tehran, Iran

Introduction Shift work and rotational shift schedule interrupt interaction of the parents with their children. Nurses, midwives, enrolled nurses, nurse's aid are obliged to have shift work. We assessed the effect of shift working of the shift workers on strengths and behavioral problems of their children, aged 7-12 years in nursing school of Tehran University of Medical Sciences.

Methods 489 shift workers drawn from private and university hospitals in Tehran city were selected along with their children's teachers. Data were collected by using Strengths and Difficulties Questionnaire (SDQ), specific to parents and teachers including scales of emotional symptoms, conduct problems, hyperactivity/ inattention, peer relationship problems and prosocial behaviors.

Results No significant relationships were found between parents' shift with strengths and difficulties problems of their children based on their self-reported questionnaire. But it was revealed that some of demographic factors have significant correlations with the scales such as number of children and their gender with conduct problems, parents educational level, gender, their shift work schedule, history of physical/psychiatric diseases of children with emotional symptoms and parents' educational degree with hyperactivity/inattention, parents' gender.

Conclusion The study didn't demonstrate impact of shift work on behavioral problems of shift workers' children. However, behavioral and emotional problems of the children were correlated with some of their parents' demographic and job related factors.

\section{7 \\ HOW TO IMPROVE POST-OPERATIVE CONSTIPATION ISSUES WITHIN ADOLESCENT PATIENTS}

doi:10.1136/archdischild-2012-302724.1897
Bowel movements can be a difficult subject to discuss both as a patient and as a professional. A way to decrease the effects of postoperative constipation is to have a dialogue with the patient about their normal defecation pattern while conducting the initial intake interview. To develop a guideline for a structured dialogue between any professional and an adolescent patient about their defecation pattern. This is done with the private nature of this subject in mind. Focusing on what the adolescent patient experiences as significant in the communication and focusing on what information is necessary to help reduce the number of days before the patient's first post-operative defecation occurs. The structured dialogue was tested in a study of 5 patients that had received operations for Idiopathic Scoliosis. Those patients will be compared to 11 other patients who were not involved in this study. The feedback from the 5 patients will be collected by the use of a questionnaire. The questionnaire has a qualitative and quantitative approach. The questionnaires have shown that the study patients feel comfortable talking with professionals about this subject when the structured dialogue is used. Since the increased focus and when utilizing the structured dialogues, the number of days before the first post-operative defecation has been reduced by $22.8 \%$. By structuring the intake interview, it has resulted in a positive effect and made the dialogue more comfortable for the patient. An increased focus has also proven to reduce the number of days between surgery and their first post-operative defecation.

\section{MATERNAL ATTACHMENT IN MOTHERS OF UNDER-25 AND OVER-35 AGE GROUPS WHO HAVE BABIES OF 1-4 MONTHS OLD WITH COLIC DIAGNOSIS}

doi:10.1136/archdischild-2012-302724.1898

'BC Demirbag, ${ }^{2} \mathrm{M}$ Kurtuncu Tanir. 'Public Health Nursing, Karadeniz Technical University, Trabzon; ${ }^{2}$ Pediatric Nursing, Zonguldak Karaelmas University, Zonguldak, Turkey

Background and Aims Maternal attachment (MA) is important in terms of mother-infant relationship. The purpose of this study was to investigate the factors that affect MA in mothers of under25 and over- 35 age groups with infants of 1-4 months old with colic diagnosis

Method The study was carried out in a family health center in Trabzon between 15 December 2010 and 15 February 2012. 47 mothers from under-25 age group and 49 mothers from over-35 age group consented to participate in the study. The study employed a socio-demographic data collection form and a Maternal Attachment Inventory (MAI). Numbers, percentages, means, standard deviations, student t-test, Fisher Exact chi-square, one-way ANOVA and correlation were used in the statistical analyses.

Results The mean MA of mothers in the under- 25 age group was found to be $95.76 \pm 6.73$, while in the over-35 age group it was found to be $92.47 \pm 8.33$. There is no statistically significant difference between the means of the MAIs of both groups ( $t=1.942 p=0.36)$. In both groups, the study found a statistically significant difference $(p<0.05)$ between the means of the MAIs and the factors of receiving prenatal education $(\mathrm{t}=-0.141 \mathrm{p}=0.01 ; \mathrm{t}=0.404 \mathrm{p}=0.01)$, mothers' education ( $\mathrm{F}=0.622 \mathrm{p}=0.02 ; \mathrm{F}=0.108 \mathrm{p}=0.03)$, planned pregnancy $(\mathrm{t}=2.617 \mathrm{p}=0.01 ; \mathrm{t}=-0.850 \mathrm{p}=0.04)$, and keeping the baby in the mother's room after birth $(\mathrm{t}=-1.201 \mathrm{p}=0.02 ; \mathrm{t}=-0.703 \mathrm{p}=0.03$ ) (respectively).

Conclusions Except for the factors of duration of breast-feeding and working, the MA factors are similar in mothers of different age groups.

\section{EFFECT OF OPEN AND CLOSED SYSTEM OF ASPIRATION ON PAIN IN NEWBORNS GIVEN MECHANICAL VENTILATION}

doi:10.1136/archdischild-2012-302724.1899 